\title{
NF-KB drives acquired resistance to a novel mutant-selective EGFR inhibitor
}

\author{
Elena Galvani ${ }^{1}$, Jing Sun ${ }^{2}$, Leticia G. Leon ${ }^{3}$, Rocco Sciarrillo ${ }^{1,4}$, Ravi S. Narayan ${ }^{5}$, \\ Robert Tjin Tham Sjin ${ }^{6}$, Kwangho Lee ${ }^{6}, K^{2}$ adoaki Ohashi ${ }^{2}$, Daniëlle A.M. Heideman, \\ Roberta R. Alfieri ${ }^{8}$, Guus J. Heynen ${ }^{9}$, René Bernards ${ }^{9}$, Egbert F. Smit ${ }^{10}$, William \\ Pao $^{2}$, Godefridus J. Peters ${ }^{1}$ and Elisa Giovannetti ${ }^{1,11}$ \\ ${ }^{1}$ Department Medical Oncology, VU University Medical Center, Amsterdam, The Netherlands \\ 2 Division of Hematology/Oncology, Department of Medicine, Vanderbilt University School of Medicine and Vanderbilt-Ingram \\ Cancer Center, Nashville, TN, USA \\ ${ }^{3}$ Instituto de Tecnologias Biomedicas, Center for Biomedical Research of the Canary Islands, University of La Laguna, \\ Tenerife, Spain \\ ${ }^{4}$ Department Hematology, VU University Medical Center, Amsterdam, The Netherlands \\ ${ }^{5}$ Department Radiation Oncology, VU University Medical Center, Amsterdam, The Netherlands \\ ${ }^{6}$ Celgene Avilomics Research, Bedford, MA, USA \\ 7 Department of Pathology, VU University Medical Center, Amsterdam, The Netherlands \\ ${ }^{8}$ Department of Clinical and Experimental Medicine, University of Parma, Parma, Italy \\ ${ }^{9}$ Division of Molecular Carcinogenesis, The Netherlands Cancer Institute, Amsterdam, The Netherlands \\ ${ }^{10}$ Department of Pulmonary Diseases, VU University Medical Center, Amsterdam, The Netherlands \\ ${ }^{11}$ Cancer Pharmacology Lab, AIRC Start-Up Unit, DIPINT, University of Pisa, Pisa, Italy
}

Correspondence to: Elisa Giovannetti, email: e.giovannetti@vumc.nl

Keywords: drug-resistance, EGFR-T790M, NSCLC, NF-KB, EMT

Received: January 10, $2015 \quad$ Accepted: April 08, 2015

Published: April 29, 2015

This is an open-access article distributed under the terms of the Creative Commons Attribution License, which permits unrestricted use, distribution, and reproduction in any medium, provided the original author and source are credited.

\section{ABSTRACT}

The clinical efficacy of EGFR tyrosine kinase inhibitors (TKIs) in non-small cell lung cancer (NSCLC) harbouring activating EGFR mutations is limited by the emergence of acquired resistance, mostly ascribed to the secondary EGFR-T790M mutation. Selective EGFR-T790M inhibitors have been proposed as a new, extremely relevant therapeutic approach. Here, we demonstrate that the novel irreversible EGFR-TKI CNX-2006, a structural analog of CO-1686, currently tested in a phase-1/2 trial, is active against in vitro and in vivo NSCLC models expressing mutant EGFR, with minimal effect on the wild-type receptor. By integration of genetic and functional analyses in isogenic cell pairs we provide evidence of the crucial role played by NF-KB1 in driving CNX-2006 acquired resistance and show that NF-KB activation may replace the oncogenic EGFR signaling in NSCLC when effective and persistent inhibition of the target is achieved in the presence of the T790M mutation. In this context, we demonstrate that the sole, either genetic or pharmacologic, inhibition of NF-KB is sufficient to reduce the viability of cells that adapted to EGFR-TKIs. Overall, our findings support the rational inhibition of members of the NF-KB pathway as a promising therapeutic option for patients who progress after treatment with novel mutant-selective EGFR-TKIs.

\section{INTRODUCTION}

Activating mutations of the epidermal growth factor receptor (EGFR) have been correlated with clinical activity of the small molecule inhibitors erlotinib, gefitinib and afatinib in non-small cell lung cancer (NSCLC) 
patients [1-3]. Despite initial efficacy, the success of EGFR tyrosine kinase inhibitors (TKIs) has been limited by the emergence of drug resistance, often ascribed to additional alterations within the target oncogene $[4,5]$.

The T790M mutation, which occurs within EGFR catalytic pocket, plays the most important role among the resistance mechanisms, arising in $\sim 60 \%$ of the cases $[3,6,7]$. Tumors harboring this mutation retain their dependency on EGFR signaling for growth, thus prompting the development of novel inhibitors of the receptor [8]. Second-generation TKIs, such as afatinib (BIBW2992) and dacomitinib (PF00299804), have shown antitumor activity against T790M-NSCLC. However, the lack of selectivity upon mutant EGFR as compared to the wild-type (WT) receptor, and evidence of acquired resistance to second-generation TKIs driven by the same T790M mutation, emphasized the need to develop more potent and specific agents against this mutation [9-11]. Selective EGFR-T790M inhibitors, including CO-1686 [12] and AZD9291 [13], have been proposed as alternative salvage therapies and are currently undergoing clinical development in patients who developed the T790M mutation (NCT01526928, NCT01802632).

In this study, we demonstrated the in vitro and in vivo selectivity and efficacy of the novel irreversible EGFR-TKI CNX-2006, a structural analog of CO-1686, in preclinical NSCLC models harboring activating mutations and the T790M. A comparable activity was observed in vitro for CO-1686. Furthermore, we developed isogenic pairs of CNX-2006-sensitive and -resistant cancer cells to address the mechanisms of resistance that may emerge upon constant and selective inhibition of the EGFRT790M oncogene. By integrating genetic and functional studies we demonstrated the key role of $\mathrm{NF}-\kappa \mathrm{B} 1$ in driving adaptive resistance to $\mathrm{CNX}-2006$ both through overexpression and constitutive activation. Finally, we showed that the inhibition of members of the NF- $\kappa \mathrm{B}$ pathway effectively reduced CNX-2006-resistant cells proliferation and survival, thus supporting innovative therapeutic strategies for patients who progress after treatment with novel mutant-selective EGFR-TKIs.

\section{RESULTS}

\section{CNX-2006 selectively inhibits mutant EGFR in vitro}

CNX-2006 is structurally related to CO-1686 (Figure 1A), and acts as a potent mutant-selective EGFR inhibitor through covalent interaction with the highly conserved Cys 797 residue in the kinase domain of EGFR (Supplementary Figure 1A-1C).

The efficacy of CNX-2006 against cells expressing WT or mutant EGFR was evaluated in surrogate kinase assays and tumor cell lines. Similar to erlotinib and afatinib, CNX-2006 readily inhibited EGFR phosphorylation in $293 \mathrm{H}$ cells harbouring either the exon 19 delE746-A750 or the L858R variant (Supplementary Figure 2A). In NSCLC cells expressing the above mentioned activating mutations (PC9 and HCC-827 cells), CNX-2006 concentrations ranging between 55 and $104 \mathrm{nM}$ were sufficient to reduce to $50 \%\left(\mathrm{IC}_{50}\right)$ the phosphorylation of EGFR after 2 hours treatment (Figure 1B). In cells expressing either EGFR-T790M alone or the T790M mutation in cis with activating mutations, CNX-2006 effectively inhibited the phosphorylation of the receptor at low nanomolar concentrations while no effect was observed after treatment with erlotinib (Figure $1 \mathrm{~B}$ and Supplementary Figure 2A). Particularly, $\mathrm{IC}_{50} \mathrm{~s}$ of about 46 and $61 \mathrm{nM}$ were obtained after 2 hours treatment with CNX-2006 in the NSCLC cell lines NCI-H1975 and PC9GR4, respectively (Figure 1B). Importantly, while both erlotinib and afatinib inhibited the activity of the WT-receptor at low nanomolar concentrations, CNX2006 affected the WT-EGFR only at concentrations which are over 10-fold higher than the ones necessary to inhibit mutated receptor (Figure 1B and Supplementary Figure 2A).

The efficacy of CNX-2006 was also tested against rare EGFR mutations, including EGFR-G719S, -ex19ins (I744-K745insKIPVAI), -L861Q, -ex20ins (H773V774HVdup), and -T854A. CNX-2006 was as active as erlotinib against the former three variants of the receptor. Partial sensitivity to CNX-2006 was also observed in EGFR-T854A cells, while no effect was detected in cells transfected with the ex20ins variant of the receptor (Supplementary Figure 2B).

The selectivity of the inhibitor on the target was tested in a panel of 62 recombinant protein kinases using the radiometric assay HotSpot [14]. Eleven kinases, including EGFR-L858R/T790M and WT-EGFR, showed inhibition $>50 \%$ after treatment with $1 \mu \mathrm{M}$ CNX-2006 (Figure 1C and Supplementary Table 1). The most effective inhibition, about $95.96 \%$, was observed against mutant EGFR, and high levels of inhibition were also observed for EGFR-sequence-related kinases. The only exception to this cluster was the cell cycle checkpoint Chk2, member of the calcium and calmodulin-regulated kinases. When tested in NCI-H1975 cells, CNX-2006 showed a strong profile of inhibition of EGFR downstream signaling pathways relative to DMSO treated cells. One $\mu \mathrm{M}$ CNX-2006 reduced the phosphorylation of several kinase substrates in a peptides based array, including different members of the MAPK, PI3K, Src and CDK families (Supplementary Table 2 and 3). In the same conditions, no evidence of inhibition of either EGFR or downstream signaling pathway was achieved by $1 \mu \mathrm{M}$ gefitinib in NCI-H1975 (Supplementary Table 2). 


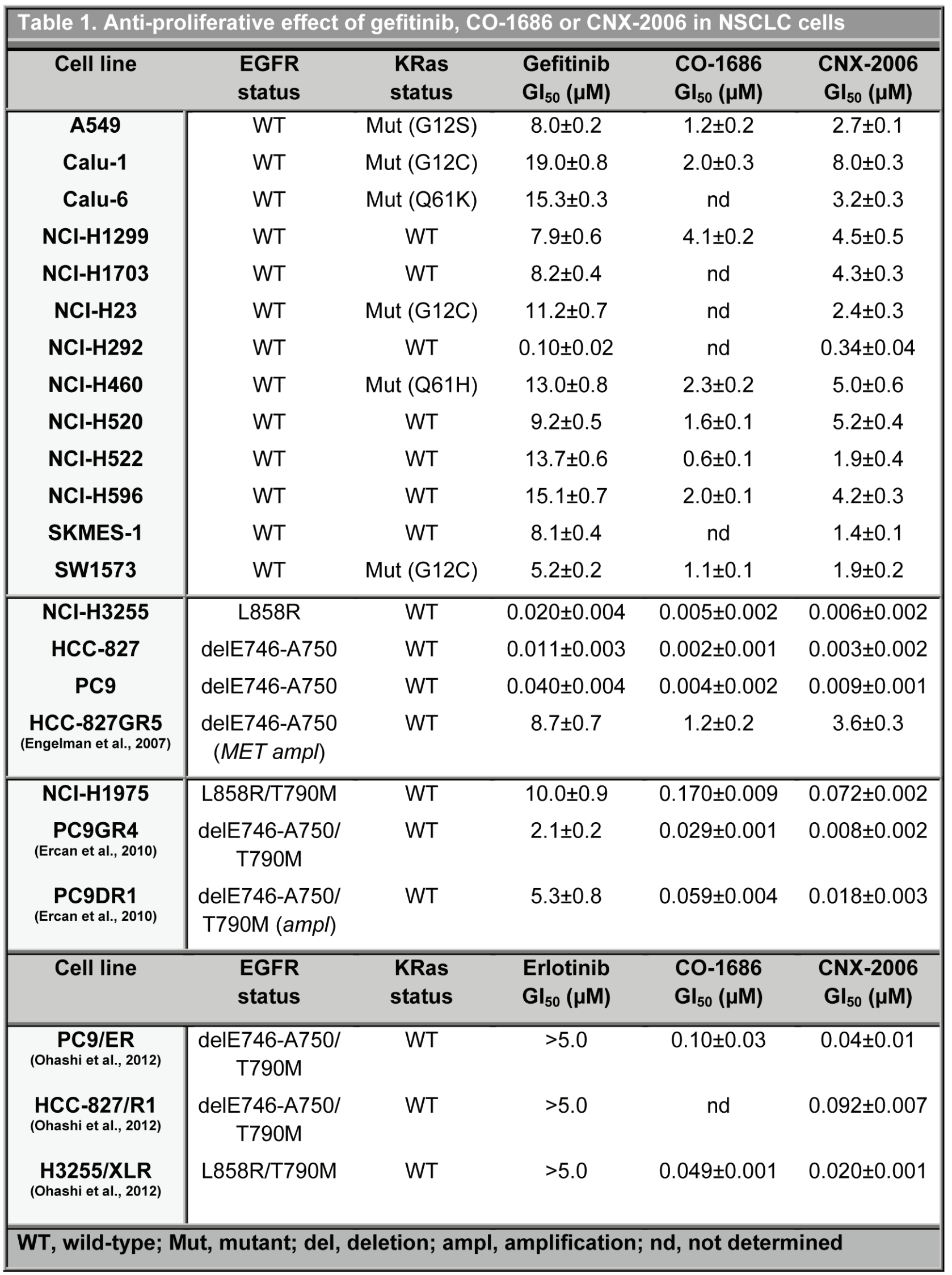




\section{CNX-2006 inhibits mutant-EGFR cell proliferation by inducing apoptosis in vitro}

In a panel of 23 NSCLC cell lines, the range of variation in sensitivity to CNX-2006, expressed as 50\% growth inhibition concentration $\left(\mathrm{GI}_{50}\right)$, was between 3 and $8000 \mathrm{nM}$ (Table 1). Despite CO-1686 and CNX2006 displayed comparable activity in cells expressing mutated EGFR, a higher selectivity was observed with the latter compound due to its more limited activity in cells harbouring the wild-type receptor (Table 1). Importantly, CNX-2006 was up to 290 -fold more active than gefitinib and erlotinib, and 55-fold more effective than second-generation EGFR-TKIs, in PC9DR1 cells carrying a focal amplification of EGFR-T790M (Figure 1D) [9]. Interestingly, resistance to gefitinib driven by MET amplification resulted in resistance to both CNX2006 and CO-1686, with over 1000-fold drop in drug activity in HCC-827GR5 cells compared to parental cells [15]. The exceptional activity of the inhibitor in EGFRT790M cells was further confirmed in three-dimensional tumor spheroids derived from NCI-H1975 cells. After 96 hours treatment with $1 \mu \mathrm{M}$ CNX-2006, the initial spheroids volume was reduced of about $40 \%$, suggesting the ability of the inhibitor to penetrate multicellular

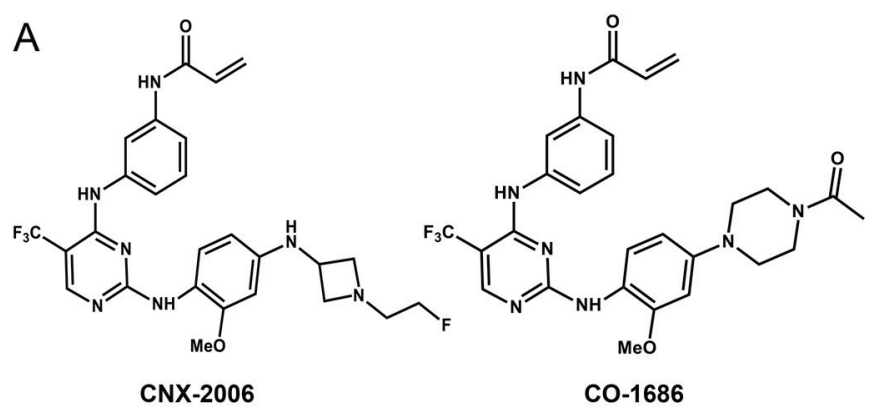

B [CNX-2006], nM
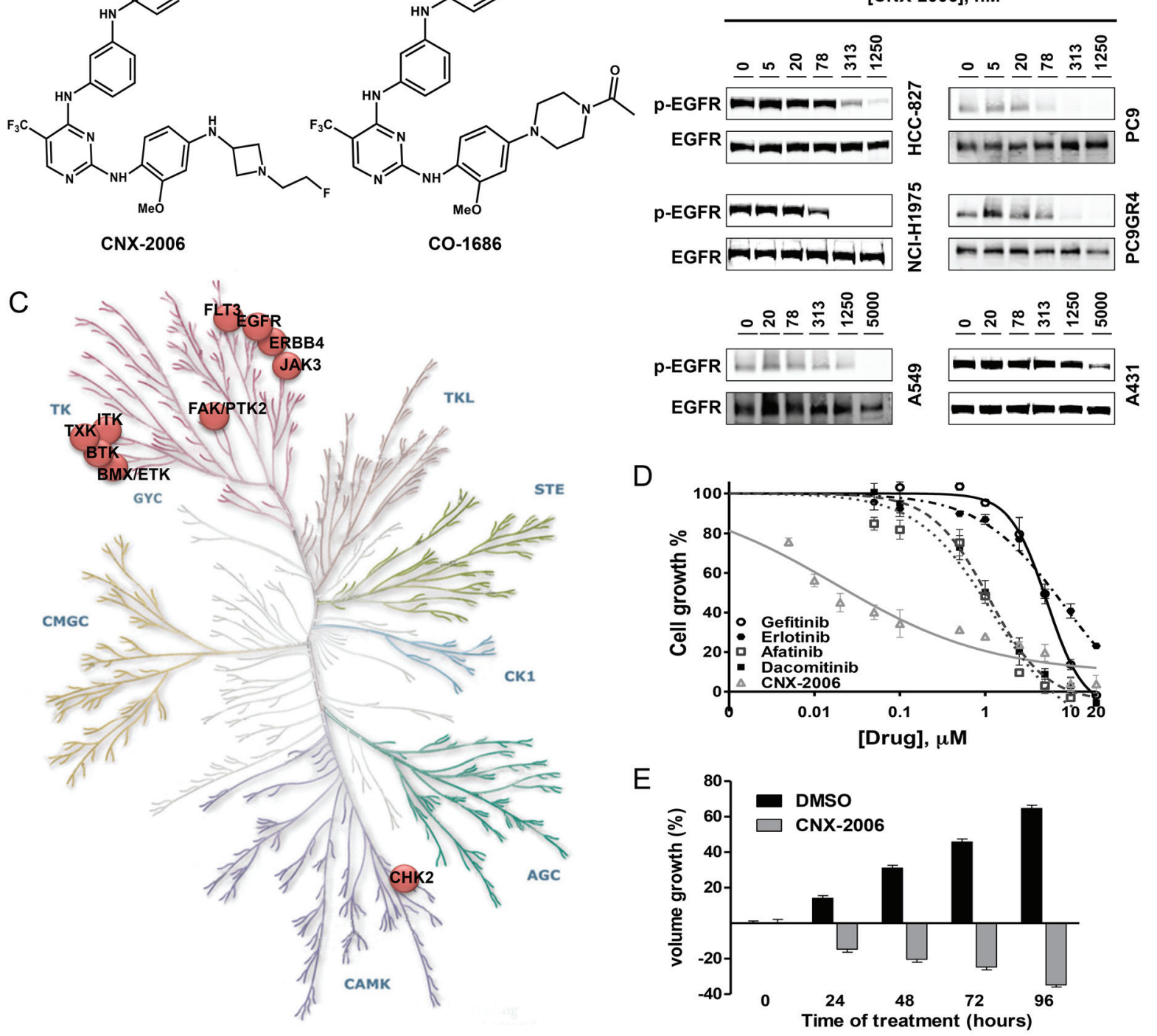

Figure 1: In vitro activity of CNX-2006. A. Molecular structure of CNX-2006 and CO-1686; B. EGFR phosphorylation inhibition evaluated after 2 hours treatment with $0.1 \%$ DMSO or the indicated concentrations of CNX-2006; C. kinase inhibition profile of $1 \mu \mathrm{M}$ CNX-2006 in the presence of $100 \mu \mathrm{M}$ ATP. The dots indicate enzymes that were inhibited $>50 \%$ by the inhibitor relative to DMSO.

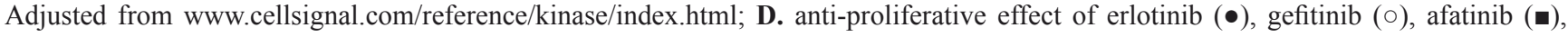
dacomitinib $(\square)$ and CNX-2006 $(\Delta)$ in PC9DR1 cells. Data plotted as mean \pm SEM; E. effect of 0.1\% DMSO or $1 \mu$ M CNX-2006 in NCIH1975-derived tumor spheres. The bar graph shows the mean \pm SEM of the percentage of spheroids volume growth normalized to the volume at the time 0 treatment. 


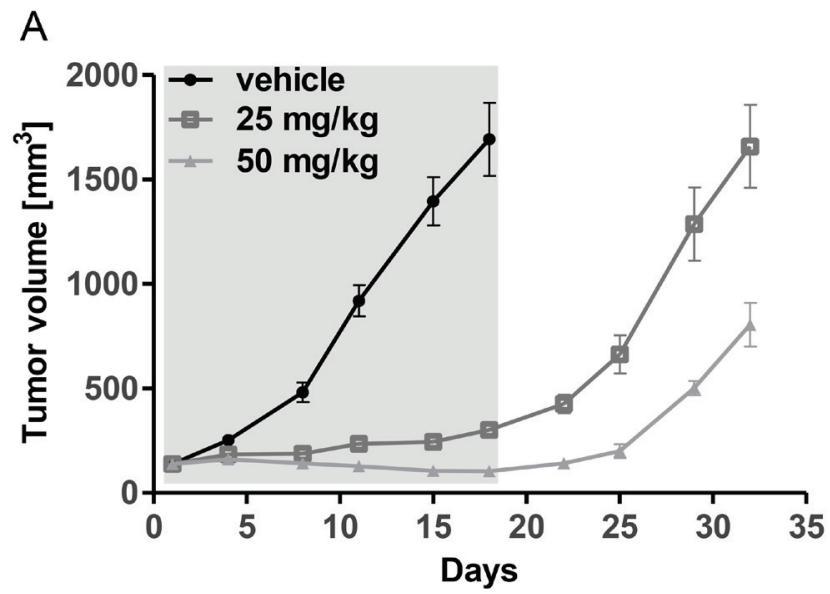

$\mathrm{B}$

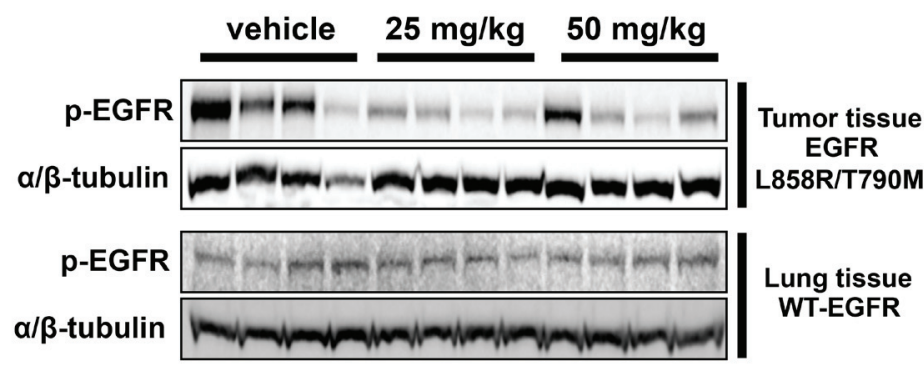

Figure 2: In vivo activity of CNX-2006. A. Tumor volume growth in xenografts during (day 0-17, grey background) and after (day 18-32) IP administration of vehicle or CNX-2006 at 25 or $50 \mathrm{mg} / \mathrm{kg}$; B. inhibition of EGFR phosphorylation 1 hour after IP administration of vehicle or CNX-2006 at 25 or $50 \mathrm{mg} / \mathrm{kg}$ as determined by immunoblot. Lysates were obtained from tumor and normal lung tissue of 4 mice per group.

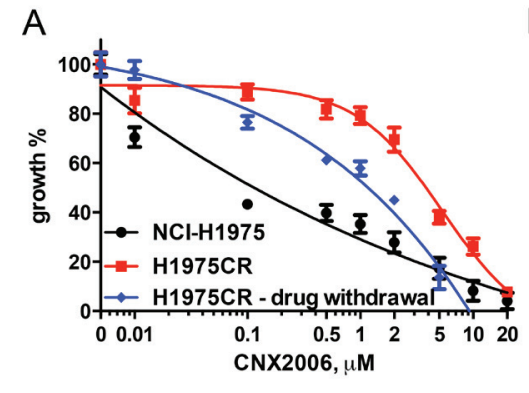

C

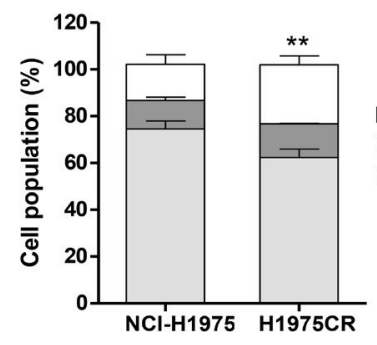

$\mathrm{B}$

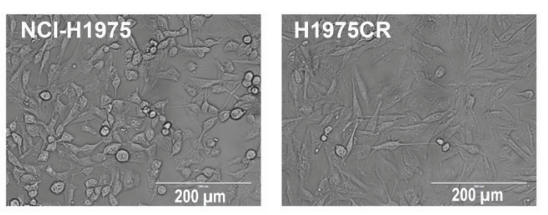

D

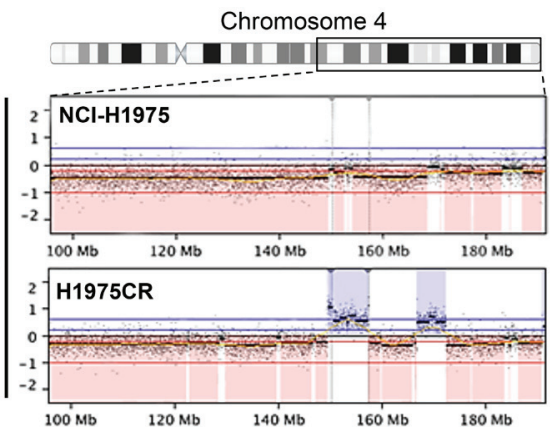

Figure 3: NCI-H1975-derived CNX-2006-resistant cells. A. Anti-proliferative effect of 72 hours treatment with $0.01-20 \mu \mathrm{M} \mathrm{CNX}$ 2006 in NCI-H1975 and H1975CR cells continuously cultured in the presence of the drug or after 3 months of drug withdrawal. The mean \pm SEM is plotted for all the tested concentrations; B. representative picture of H1975CR and NCI-H1975 cells in standard culture conditions; C. cell cycle distribution of NCI-H1975 and H1975CR cells 24 hours after plating. ${ }^{*} P<0.05$ relative to G2-M phase in NCI-H1975 cells; D. differential copy number variation in chromosome 4 in parental and resistant cells as determined by array CGH. Red, loss; blue, gain vs. XX/XY control. 
structures (Figure 1E). Furthermore, increase of cellular fragments in Sub-G1 phase, chromatin condensation and nuclear fragmentation were observed after treatment with the EGFR-TKI (Supplementary Figure 3A). Moreover, reduction of the mitochondrial membrane potential, as measured by DiOC6 staining, and loss of membrane integrity by AnnexinV, showed that 24 hours treatment with CNX-2006 effectively induced $\sim 16 \%$ apoptosis in NCI-H1975 cells (Supplementary Figure 3B-3C).

\section{CNX-2006 inhibits EGFR-T790M tumor growth in vivo}

Consistent with its in vitro anti-proliferative effect in cells carrying EGFR-T790M, CNX-2006 daily dosed at either 25 or $50 \mathrm{mg} / \mathrm{kg}$ inhibited the growth of subcutaneous NCI-H1975-derived tumors (Figure 2A). In the groups treated with the inhibitor, tumor growth was observed only after drug withdrawal (over day $18^{\text {th }}$ in Figure 2A). Reduction of target phosphorylation was observed 1 hour after the administration of both the doses of the drug in tumor tissue expressing mutant EGFR. Remarkably, as observed in vitro, CNX-2006 did not affect the activation of the wild-type receptor expressed in normal lung tissue
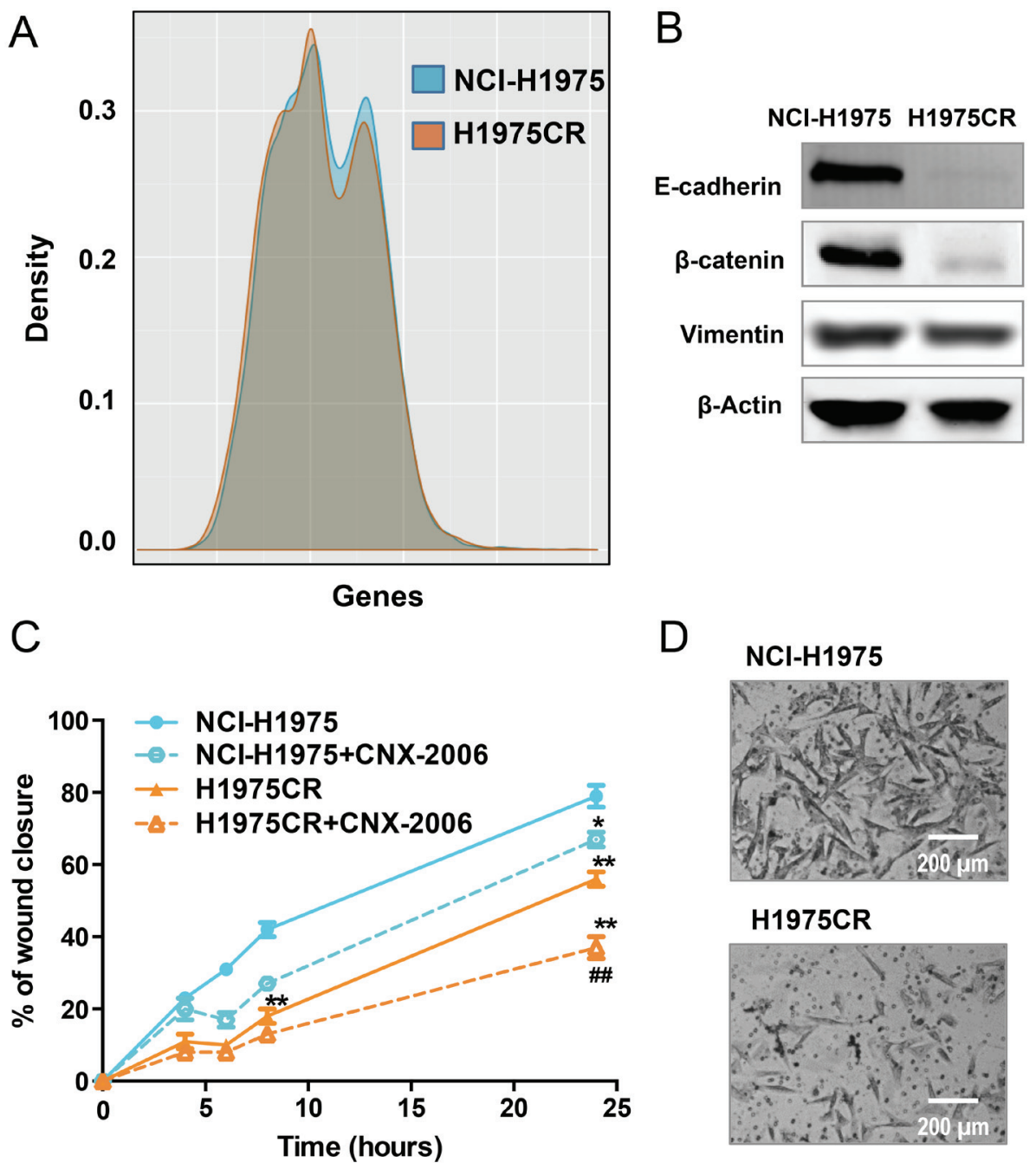

Figure 4: Migration and invasion. A. Graphical representation of whole transcriptome comparing NCI-H1975 and H1975CR cells; B. E-cadherin, $\beta$-catenin and vimentin protein expression in NCI-H1975 vs H1975CR cells as detected by immunoblot. $\beta$-actin was included as a loading control; $\mathbf{C}$. cell migration as measured by wound healing assay. The percentage of migration is relative to the treatment starting point $(t=0)$ with $0.1 \%$ DMSO or $1 \mu \mathrm{M} \mathrm{CNX}-2006$ and is plotted as mean \pm SEM of four replicates in 3 independent experiments. $* * P<$ 0.01 vs NCI-H1975 DMSO-treated cells, ${ }^{\#} P<0.01$ vs H1975CR DMSO-treated cells; D. representative images of cellular invasiveness through the matrigel in NCI-H1975 vs H1975CR cells. 
(Figure 2B and Supplementary Figure 4A). Of note, CNX2006 accumulation was observed 1 hour after the treatment in lungs, with concentrations up to $\sim 13$ and $\sim 7$-fold higher than in plasma and liver, respectively (Supplementary Figure 4B). A similar behavior has previously been reported for gefitinib that reached up to 10 -fold higher concentrations in lung tissue as compared to plasma 2 hours after either intravenous or oral administration [16, 17]. This accumulation has been more recently associated with active uptake of the first-generation EGFR-TKI in NSCLC cells by various members of the solute carrier (SLC) superfamily of transporters [18, 19]. The tissue specific distribution of various SLCs having CNX-2006 as a substrate may explain its preferential accumulation in lungs as compared to liver or plasma.

\section{Chromosomal instability in CNX-2006-resistant cells affects cell differentiation and proliferation}

In vitro acquired resistance to CNX-2006 was achieved by applying escalating concentrations (up to 1 $\mu \mathrm{M})$ in NCI-H1975 cells. After 8-10 months, we isolated a pool of CNX-2006-resistant (CR) cells which was over 60 -fold less sensitive to the $\operatorname{drug}\left(\mathrm{GI}_{50}=4.6 \mu \mathrm{M}\right)$ compared to the parental cell line (Figure 3A). Cross-resistance to the quinazoline-derivatives afatinib and dacomitinib as well as CO-1686 $\left(\mathrm{GI}_{50} \mathrm{~s}>1 \mu \mathrm{M}\right)$ was also observed (data not shown). The obtained resistant cells showed increased dimensions and acquired spindle-like morphology, a shorter doubling time and a different cell cycle distribution compared to parental cells. A significant increase $(P<$ 0.01 ) in the number of cells in G2-M phase was observed in H1975CR compared to NCI-1975 cells (Figure 3B3C). After over 3 months of drug withdrawal, H1975CR sensitivity to CNX-2006 was partially restored, with $\mathrm{GI}_{50}$ at 72 hours treatment of $940 \mathrm{nM}$ (Figure 3A). EGFRindependent growth and proliferation were confirmed in H1975CR cells by transient EGFR knockdown (Supplementary Figure 5A-5B).

Genome-wide high-resolution analysis of DNA copy number variations was performed by array-CGH in H1975CR cells and compared to the parental cells. Chromosomal imbalances in the resistant cells mostly overlapped the NCI-H1975 cells (Supplementary Figure 6A), including common DNA aberrations in lung cancer, such as amplifications in locus $7 \mathrm{p} 11.2$, containing the $E G F R$ gene, and gains at 5p15.33-p15.31, 1q21-q25, 8q24.21 and 11q13 loci [http://AtlasGeneticsOncology. org, 20]. Large deletions were observed in 9p24.1-p23 and 13 q21 loci which were previously associated with lung adenocarcinomas [21]. Three large regions emerged in H1975CR cells that were differentially altered compared to the parental cells, i.e. amplification in chromosome 4, and deletions in chromosomes 2 and 8. Multiple genes involved in cell survival and motility regulation, such as
MYCN, NRBP1, EPCAM, PKP4, RHOB, SNAI2, ASPH, $G D A P 1$ and $I L 7$, were included in the large deletions in 2p24.3-p21 and 8q12.3-q13.3 loci (Supplementary Figure 6B). Similarly, the 4q31.2 locus has previously been related to lung cancer development (Figure 3D) [22]. Several genes important for cell differentiation and proliferation are included in this locus, such as the Hedgehog-interacting protein, Glycophorin A, IL15, GRB2-associated binding protein-1 and SH3D19. Overexpression of these genes in H1975CR cells was confirmed by RNA-seq (Supplementary Dataset 1).

\section{Expression of altered cell adhesion patterns reduced cell motility in $\mathrm{H} 1975 \mathrm{CR}$}

Further comparison of NCI-H1975 and H1975CR cells transcriptomes showed similar expression patterns, with only few exceptions (Figure 4A). The analysis of RNA-seq using beta-binomial distribution [23] followed by KEGG pathway analysis (Kanehisa Laboratories; Kyoto University), and TopHat2 coupled Cufflinks analysis, demonstrated a differential expression of genes involved in cell-cell and cell-extracellular matrix (ECM) interaction. Specifically, decreased expression of $\mathrm{CDH}$ (epithelial cadherin: E-cadherin) was observed in CNX2006-resistant cells, further confirmed by immunoblot analysis (Figure 4B). A concomitant reduction of $\beta$-catenin was also observed in H1975CR cells (Figure 4B). Given the role of cell adhesion in cancer aggressiveness, we investigated the migratory and invasive behavior of H1975CR cells. Surprisingly, the H1975CR cells displayed a significantly reduced motility $(P<0.01)$ in a wound-healing assay compared to parental cells, as well as reduced invasiveness through the ECM (Figure 4C-4D). Both behaviors were further reduced by the treatment with $1 \mu \mathrm{M}$ CNX-2006.

To explore the mechanisms underlying these results, we evaluated the effect of $1 \mu \mathrm{M}$ CNX-2006 on EGFR phosphorylation, as well as on the activation of its major effectors. After 2 hours treatment, EGFR phosphorylation was inhibited in both NCI-H1975 and H1975CR cells with concomitant reduction of Akt and ERK1/2 activation (Figure 5A). Despite their proliferation profile was unaltered following EGFR knockdown, CNX-resistant cells conserved a certain level of dependency on the oncogene signaling for cellular motility as demonstrated by the retained effect of the drug in this process.

\section{Overexpression and constitutive activation of NF- $\kappa \mathrm{B} 1$ drive adaptive resistance to CNX-2006}

Genetic characterization was performed for recurrent EGFR (exons 18-21), KRAS (exons 2-3), BRAF (exon 15) and PIK3CA (exons 9 and 20) mutations in H1975CR cells [24]. After CNX-2006 resistance 

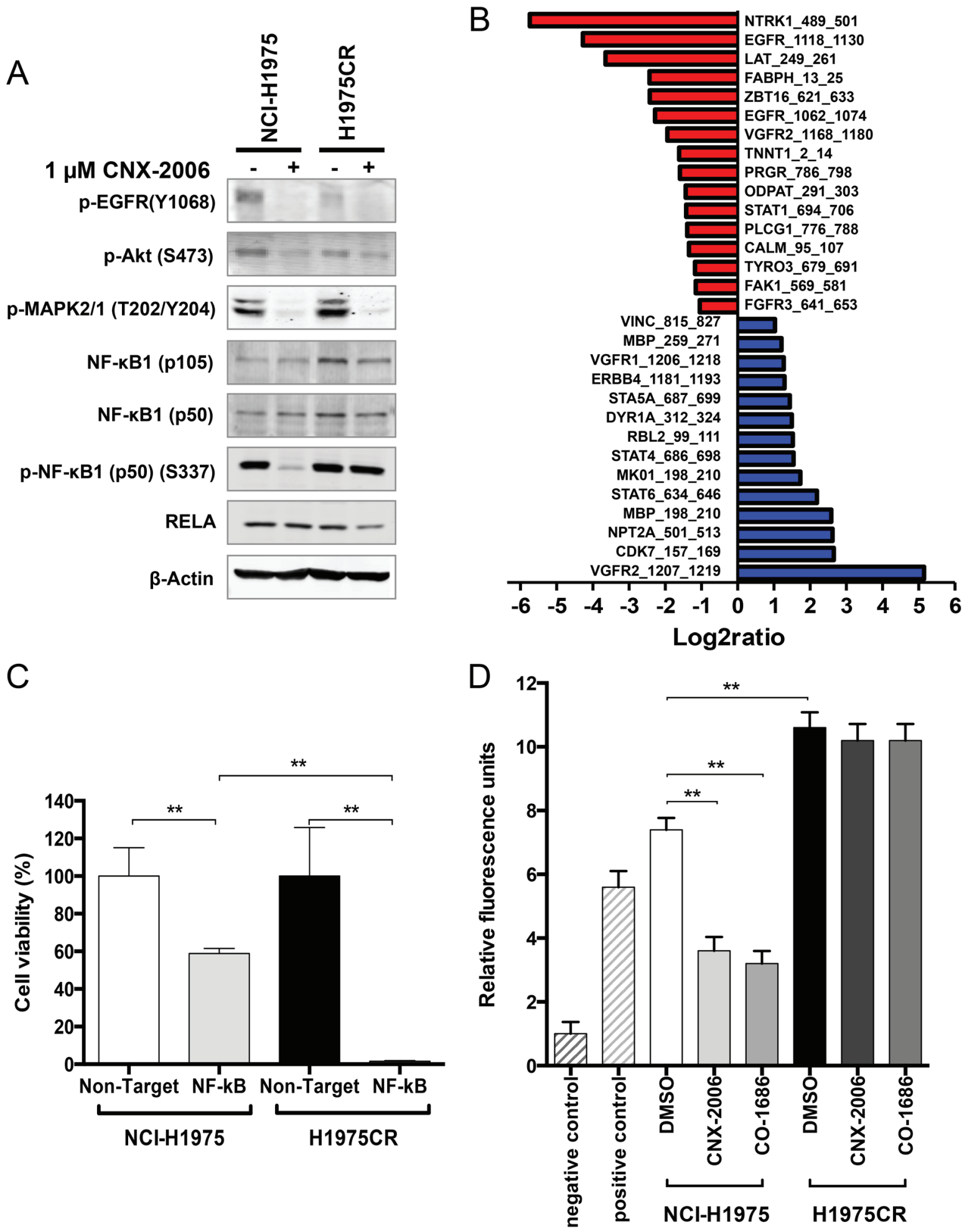

Figure 5: NF-кB-mediated resistance to CNX-2006. A. Modulation of key signaling proteins in NCI-H1975 and H1975CR cells

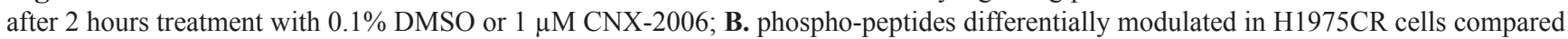
to NCI-H1975 cells. A fold-change $>2$ was chosen as cutoff. Red, reduction; blue, enhancement; C. effect of NF- $\kappa \mathrm{B}$ silencing on cell viability in NCI-H1975 and H1975CR as assessed by cell count after DAPI-staining. Cell viability was determined 72 hours post-siRNA transfection and Non-Target siRNA transfected cells were used as control. Data plotted as mean \pm SEM; D. NF-kB activity expressed in relative fluorescence units as compared to the negative control. Cells were treated with $0.1 \%$ DMSO, $1 \mu \mathrm{M} \mathrm{CNX}-2006$ or $1 \mu \mathrm{M}$ CO-1686 for 6 hours. Data plotted as mean \pm SEM. ** $P<0.01$. 
development, EGFR-L858R/T790M was the only detected target alteration, and no additional mutations emerged in any of the other candidate genes. Furthermore, differently from previously reported results describing resistance to third generation EGFR-TKIs [25, 26], neither reduced IGFBP3 gene expression nor MAPK1 amplification was observed in CNX-2006-resistant cells by RNA-seq and aCGH.

The reduced expression of $\mathrm{CDH} 1$ observed in H1975CR cells, and previous results on the involvement of EMT in NSCLC resistance to EGFR-TKI treatment $[12,27,28]$, led us to investigate the role of this process in resistance to CNX-2006. Gene expression analysis of the 76 genes included in the EMT signature developed by Byers and colleagues was performed [29]. A broad reduction in the expression of epithelial markers was observed in H1975CR cells compared to parental cells, while there was only slight or no increase in mesenchymal markers (Supplementary Figure 7A). Results were validated by qRT-PCR or immunoblot for various EMT markers, including CLDN4, CLDN7, EPCAM, ZEB1, FN1, AXL, MMP2 and vimentin (Figure 4B and Supplementary Figure 7B). A key role for EMT in resistance to CNX-2006 was excluded on the basis of these results.

Activated kinases were investigated in parental and H1975CR cells by high-throughput array to unravel diversely triggered pathways that may drive the resistance to CNX-2006. A pool of 30 differentially phosphorylated ( $>2$-fold) peptides was identified in CNX2006-resistant cells compared to parental cells (Figure 5B and Supplementary Table 2). The phosphorylation sites on the peptides were associated with 24 kinases, 13 of which were downregulated in H1975CR cells, including FGFR3, FAK1 and EGFR. Conversely, 11 kinases were upregulated in the resistant cells, including ERBB4, PKC, MAPK1, and JAK. About 65\% reduction in EGFR autophosphorylation and $\sim 40 \%$ enhancement in MAPK1 (p42) activation was confirmed by immunoblot in H1975CR cells compared to NCI-H1975 cells (Figure $5 \mathrm{~A})$. Interestingly, in line with recent results showing the involvement of NF- $\mathrm{B}$ signaling in modulating lung cancer dependence upon EGFR oncogenic signaling [30], 17 of the modulated kinases could directly or indirectly be linked to NF- $\kappa \mathrm{B}$ pathway. Immunoblot analysis revealed

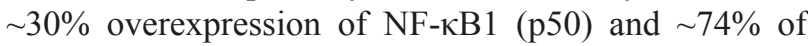
its precursor (p105), but not RELA (p65), in CNX2006-resistant compared to the parental cells (Figure $5 \mathrm{~A})$. In line with these results, about 3 -fold increase in ATM phosphorylation was also found in resistant cells compared to NCI-H1975 (Supplementary Figure 8A).

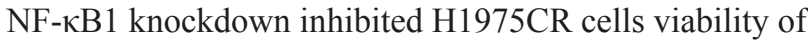
$\sim 99 \%$, while $\sim 60 \%$ of the NCI-H1975 cells survived after down-regulation of the transcription factor (Figure 5C and Supplementary Figure 8B). Data on its activation further

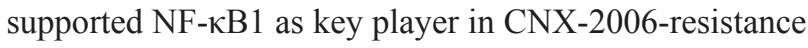

development. The treatment with $1 \mu \mathrm{M} \mathrm{CNX}-2006$ did not affect the phosphorylation of the transcription factor in H1975CR cells, while its complete inhibition was achieved under the same conditions in parental cells (Figure $5 \mathrm{~A}$ ). Basal activity of $\mathrm{NF}-\kappa \mathrm{B}$ as monitored by fluorescence was 1.45-fold higher in H1975CR than in parental cells (Figure 5D). Furthermore, the treatment with either $1 \mu \mathrm{M}$ CNX-2006 or CO-1686 caused $\sim 50 \%$ inhibition of NF- $\mathrm{KB}$ in NCI-H1975, while no effect was observed in the resistant cells under the same conditions.

\section{Pharmacological inhibition of $\mathrm{NF}-\kappa \mathrm{B}$ pathway reduces cell viability in $\mathrm{CNX}-2006-$ resistant cells}

The canonical activation of $N F-\kappa B$ relies on phosphorylation-induced degradation of $\mathrm{I} \kappa \mathrm{B}$ family members mediated by the I $\mathrm{B}$ kinase (IKK) complex and consequent nuclear translocation of $\mathrm{NF}-\kappa \mathrm{B}$ dimers [31]. Thus, we tested the effect of agents targeting the NF$\kappa \mathrm{B}$ pathway at different levels. These drugs displayed a greater efficacy in reducing cell viability of NF- $\kappa B-$ dependent H1975CR cells than parental cells (Figure 6A$6 \mathrm{~B})$. Particularly, the small molecule TPCA-1 reduced both IKK $\beta$ and IkB $\alpha$ phosphorylation of $\sim 70 \%$ in resistant cells (Supplementary Figure 9A-9B) and had 4-fold increased anti-proliferative effect in H1975CR compared to NCI-H1975 cells. Prolonged inhibition of the proteasomes by bortezomib also altered the pathway by causing $\mathrm{IkB} \alpha$ accumulation in H1975CR cells (Supplementary Figure 9C). The inhibitor effectively reduced cell viability in both resistant and parental cells, with $\mathrm{GI}_{50} \sim 16.8$ and 85.8 $\mathrm{nM}$, respectively (Figure 6A-6B). Furthermore, the PI3K/ mTOR inhibitor BEZ-235 was also tested as it has been shown to interfere with the 'atypical' NF- $\kappa \mathrm{B}$ activation pathway, which includes ATM, ATR and DNA-PK [32, 33]. The compound reduced ATM phosphorylation by $\sim 20 \%$ in CNX-2006-resistant cells where it showed over 3-fold increased anti-proliferative effect over NCI-H1975 parental cells (Figure 6A and Supplementary Figure 9D). Despite the greater activity in CNX-2006 resistant cells compared to parental cells, single agent TPCA-1 was unable to completely inhibit the pathway, as shown by the residual phosphorylation of both IKK $\beta$ and $\operatorname{IkB} \alpha$ (Supplementary Figure 9A-9B). To achieve a greater inhibition of the pro-survival signaling cascade, the NF$\kappa \mathrm{B}$ pathway inhibitors TPCA-1, bortezomib or BEZ235, were combined with CNX-2006 at their respective $\mathrm{GI}_{25}$. After 72 hours treatment, $\sim 82 \%, \sim 88 \%$ and $\sim 55 \%$ inhibition of H1975CR cell viability was observed for TPCA-1, bortezomib or BEZ-235, in combination with CNX-2006, respectively (Figure 6C).

\section{DISCUSSION}

In this study we evaluated the mechanisms of 
A

\begin{tabular}{cccc}
\hline Drug & $\begin{array}{c}\text { NCl-H1975 } \\
\text { GI50 }(\mu \mathrm{M})\end{array}$ & $\begin{array}{c}\text { H1975CR } \\
\text { GI50 }(\mu \mathrm{M})\end{array}$ & $\begin{array}{c}\text { Sensitivity } \\
\text { ratio }\end{array}$ \\
\hline CNX-2006 & 0.072 & 4.61 & 64.02 \\
TPCA-1 & 4.52 & 1.16 & 0.26 \\
BEZ-235 & 0.048 & 0.016 & 0.33 \\
Bortezomib & 0.086 & 0.017 & 0.20 \\
\hline
\end{tabular}

B
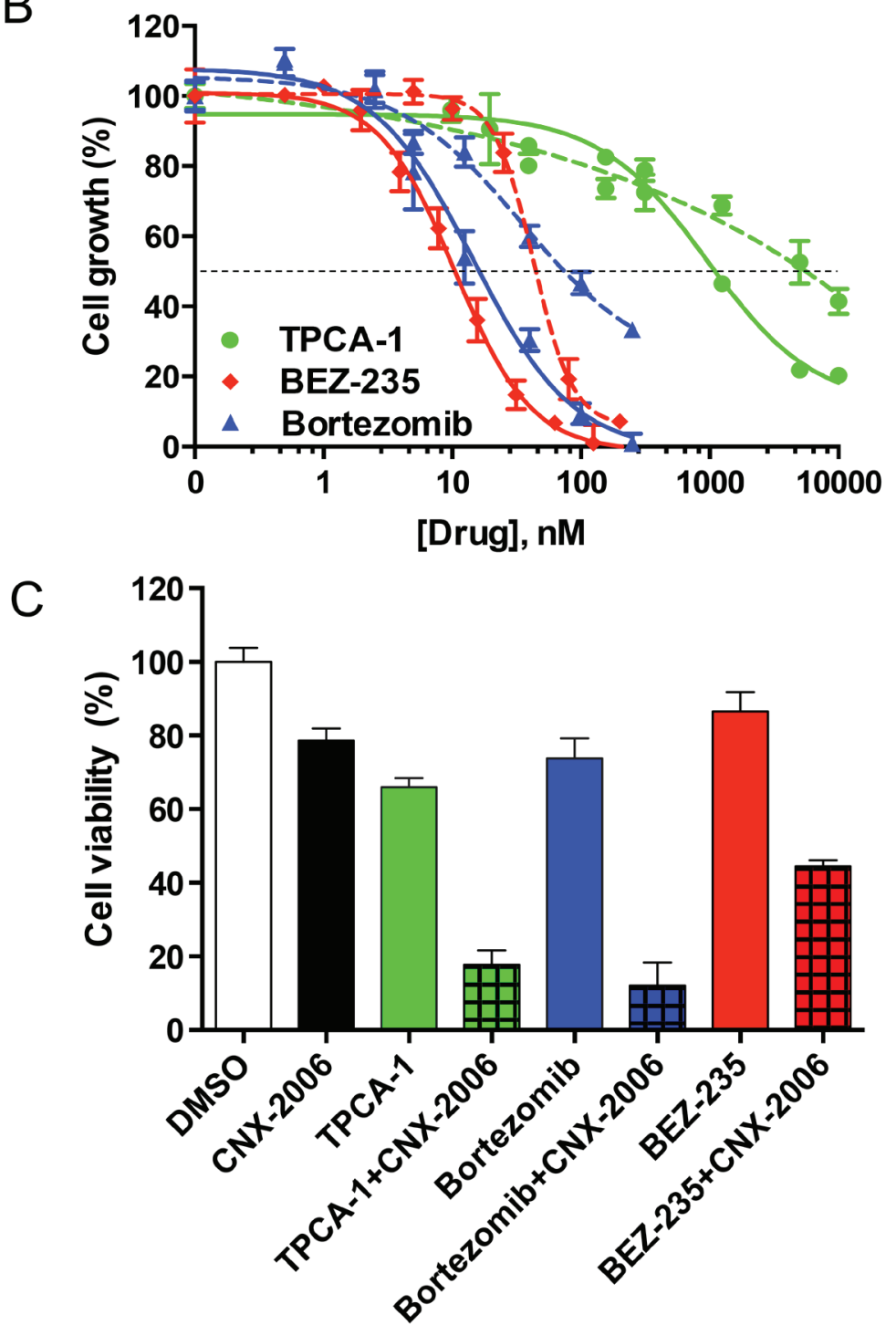

Figure 6: Targeting NF-кB pathway. A. Growth Inhibition $50\left(\mathrm{GI}_{50} \mathrm{~s}\right)$ of different drugs in NCI-H1975 and H1975CR cells after 72 hours treatment. The ratio of H1975CR vs NCI-H1975 cells GI $_{50} \mathrm{~s}$ is indicated for each drug; B. anti-proliferative effect of the tested inhibitors affecting the NF-kB pathway at different levels in H1975CR (continuous lines) and NCI-H1975 cells (dashed lines). The mean \pm SEM is plotted for each drug at the tested concentrations. The dashed black line indicates the $\mathrm{GI}_{50} ; \mathbf{C}$. antiproliferative effect of 72 hours treatment with the indicated drugs at their $\mathrm{GI}_{25}$, either as single agent or in combination with CNX-2006 in H1975CR cells. Data plotted as mean \pm SEM. $* * P<0.01$. 
resistance that may emerge by targeting EGFR-T790M in NSCLC and identified NF- $\kappa \mathrm{B}$ as key player in adaptive and reversible resistance to the novel mutant selective EGFR inhibitor CNX-2006. For the first time, we demonstrate that $\mathrm{NF}-\kappa \mathrm{B}$ pathway activation may replace the oncogene signaling in lung cancer when effective and persistent inhibition of EGFR is achieved in the presence of the T790M mutation. In this context, we show that the sole inhibition of NF- $\kappa$ B activity is sufficient to reduce the viability of cells that developed resistance to thirdgeneration EGFR-TKI by becoming independent from the signaling of the receptor.

Recent preclinical studies reported promising results in terms of greater efficacy and selectivity against EGFRT790M by either reversible indolocarbazole-based or irreversible pyrimidine-based TKIs, such as WZ4002, AZD9291 and CO-1686 [12, 13, 34, 35]. Our results demonstrate that CNX-2006 abrogates mutant-EGFR activity, both in vitro and in vivo. Conversely, the weak inhibition of WT-EGFR suggests a more limited toxicity of CNX-2006 compared to first- and second-generation TKIs [36, 37]. CNX-2006 also showed good stability and favorable pharmacokinetics, and potently inhibited the growth of tumor spheres and subcutaneous xenografts.

Given the clinical challenge represented by the emergence of drug resistance against novel TKIs, acquired resistance to CNX-2006 was investigated as an important scenario to develop and test alternative treatment strategies. To address this aim we developed isogenic pairs of drug-sensitive and -resistant cancer cells, a strategy which has already been successfully applied to model EGFR-TKIs resistance in NSCLC [15, 27, 28, 38, 39].

In contrast to recent findings reporting the acquisition of additional EGFR mutations driving the resistance to WZ4002 [26, 40], we did not identify any additional EGFR mutation that may explain the secondary resistance to CNX-2006. Similarly, no evidence of promoter-methylation-driven repression of IGFBP3 expression and consequent activation of the IGF1R pathway, a mechanism previously associated with WZ4002-resistance in PC9 cells [25], was observed in H1975CR. Despite H1975CR displayed increased MAPK1 phosphorylation compared to NCI-H1975 cells, neither genomic amplification nor enhanced expression of MAPK1 was observed in CNX-2006-resistant cells, all of which have been described to drive WZ4002 resistance in PC9GR cells [26]. Furthermore, unlike previous findings in H1975 WZR cells [26], MAPK1 phosphorylation was completely abrogated by CNX-2006 treatment in $\mathrm{H} 1975 \mathrm{CR}$ cells and no effect on cell viability was observed after treatment with the MEK1/2 inhibitor MEK162 (data not shown).

Our studies on CNX-2006-resistance demonstrated RNA-based enrichment of deregulated cell-cell and cellECM adhesion patterns. In particular, E-cadherin and $\beta$-catenin degradation after cell junctions disruption has been previously associated with tumor dedifferentiation, invasiveness and metastases formation [41]. Furthermore, a relevant role for EMT in resistance to EGFR and PI3K/ Akt inhibitors has recently been demonstrated in NSCLC cell lines and patient samples, leading to the development of a 76-gene signature defining the transformation process [29]. A similar signature has been observed to drive acquired resistance to CO-1686 in both NCI-H1975 and HCC-827 cells [12]. However, while confirming a predictive role of altered $\mathrm{E}$-cadherin/ $\beta$-catenin expression in response to EGFR-TKIs in NSCLC [42], our results showed a reduction in the invasive behavior of CNX-2006resistant cells. A possible explanation for this discrepancy is the down-regulation of FAK1 activity observed in H1975CR cells, which is critical for growth factor and integrin-induced cell migration [43]. Interestingly, H1975CR cells motility was further inhibited by CNX2006 treatment, thus supporting the use of the inhibitor as maintenance treatment after the emergence of drugresistance, as reported previously for other EGFR-TKIs [44].

In the last decade, a critical role for NF- $\kappa \mathrm{B}$ pathway in lung cancer has been described in chemical-induced lung tumor models [45] as well as in models harboring commonly mutated genes such as KRAS and Trp53 [46]. Although the EGF-EGFR axis is known to activate NF- $\kappa \mathrm{B}$ signalling pathway through different mediators $[47,48]$, erlotinib treatment did not affect NF- $\kappa \mathrm{B}$ activation in a variety of cancer cells, thus highlighting the complexity of a pathway for which constitutive activation has been associated to treatment resistance in different cancer types [49-51]. Recently, Bivona and colleagues provided evidence of the involvement of NF- $\mathrm{BB}$ in modulating lung cancer dependence upon EGFR oncogenic signaling and consequently in resistance to erlotinib [30]. The study showed how inhibition of NF- $\mathrm{KB}$ signaling enhances erlotinib-induced apoptosis in lung cancer cells harboring activating mutations of EGFR. While the study by Bivona et al. limited the relevance of the pathway to non-T790M

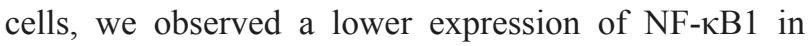
PC9 as compared to PC9GR4 cells, where resistance to gefitinib is driven by the acquisition of the T790M mutation (data not shown).

In the present study, we demonstrate that persistent $\mathrm{NF}-\kappa \mathrm{B}$ activation can intervene at different anti-EGFR treatment stages and drive drug resistance in NSCLCs carrying the T790M mutation. Despite its hyperactivation in H1975CR cells, NF- $\kappa \mathrm{B}$ signaling remains tightly regulated by IKK and $\mathrm{I} \kappa \mathrm{B}$. Indeed, we showed for the first time that the sole inhibition of carefully selected members of the NF- $\kappa \mathrm{B}$ pathway, including IKK $\beta$, is sufficient to successfully antagonize tumor growth and overcame resistance to CNX-2006. However, a possible explanation for NF- $\kappa \mathrm{B}$ activation in $\mathrm{H} 1975 \mathrm{CR}$ cells may reside in a cytokine-mediated upregulation of IKK family members. Several cytokines were differentially modulated in CNX- 
2006-resistant compared to NCI-H1975 cells at gene expression level, including some members of the TNF family as well as interleukins which have previously been shown to promote IKK activation (Supplementary Dataset 1).

In conclusion, this study demonstrates the excellent efficacy of the novel mutant selective EGFR inhibitor CNX-2006 in several representative preclinical models of NSCLC. Furthermore, we provide evidence of the key role of NF- $\kappa B$ signaling in driving lung cancer resistance when effective and persistent inhibition of EGFR is achieved in the presence of the T790M mutation. Whether NF$\kappa \mathrm{B}$ upregulation existed prior to $\mathrm{CNX}-2006$ treatment in a subset of NCI-H1975 cells that expanded under the pressure of drug selection, or emerged as adaptive response to compensate the inhibition of EGFR is still under investigation. However, regardless bortezomib limited efficacy in unselected NSCLC patients [52], we demonstrated that proteasome inhibition might represent a valid therapeutic strategy to bypass NF- $\mathrm{B}$-mediated EGFR-TKI resistance in selected patients. Furthermore, here we demonstrated that NF- $\kappa \mathrm{B}$ inhibition is also a valid strategy to enhance the effect of third-generation EGFRTKIs in NSCLC expressing EGFR-T790M. Similarly, previous studies reported a role for $\mathrm{NF}-\kappa \mathrm{B}$ inhibition in sensitizing cells to erlotinib-induced cell death $[26,44]$. This strategy is currently evaluated in a phase $1 / 2$ clinical trial by combining erlotinib and quinacrine in NSCLCs (NCT01839955). Our results should pave the way for molecular profiling on multiple levels in patients treated with mutant-selective EGFR inhibitors and support the use of novel treatment strategies to either overcome or delay the escape from oncogene addiction in EGFR-mutant NSCLC.

\section{MATERIALS AND METHODS}

Note that additional materials and methods are included in the Supplemental Methods file.

\section{Drugs and chemicals}

The synthesis of CNX-2006 is described in the Supplemental Methods. CO-1686 and gefitinib were a generous gift from Clovis Oncology (San Francisco, CA) and AstraZeneca (Macclesfield, UK), respectively. Additional drugs and chemicals are described in the Supplemental Methods.

\section{Cell culture}

The human NSCLC cell lines A549, Calu-1, Calu6, NCI-H460, NCI-H292, NCI-H1299, NCI-H1730, NCI-H23， NCI-H3255， NCI-H520， NCI-H522, NCI-H596, HCC-827, SKMES-1, SW1573 and
NCI-H1975 and the human epidermoid carcinoma A431 cells were purchased from ATCC (Manassas, VA), and cultured as recommended. $293 \mathrm{H}$ cells were purchased from Invitrogen (Carlsbad, CA). PC9, PC9GR4, PC9DR1 and HCC-827 GR5 were a kind gift of Dr. Pasi A. Jänne, Harvard University, Boston, MA [13]. PC9/ER, HCC827/R1 and H3255/XLR cells are isogenic erlotinib- or XL-647-resistant lines derived from PC9, HCC-827 and NCI-H3255 cells, respectively, as previously described [53]. Additional information on cell cultures procedures is reported in the Supplemental Methods.

\section{Transfections and siRNA}

Transfections with mutant EGFR constructs were performed in $293 \mathrm{H}$ cells using pcDNA3.1(-) vectors and Lipofectamine 2000 (Invitrogen; Carlsbad, CA). Two $\mu \mathrm{g}$ DNA was used per sample as previously described [54]. EGFR mutations G719S, ex19ins, ex20ins, L861Q, T854A, T790M, and L858R/T790M were generated by site-directed mutagenesis using a WT-EGFR cDNA template as previously described [54].

Transfections with siRNA were performed on $1 \times 10^{5}$ cells/well plated into 6-well plates using Lipofectamine 2000. For all procedures, standard protocols were used according to the manufacturers' manuals. Synthetic siRNA targeting either EGFR (ID\#103549) or NF-kB1 (ID\#107297) was purchased from Applied Biosystems/ Ambion (Foster City, CA). Non-Target siRNA was used as control.

\section{Tumor spheres}

Spheroids from NCI-H1975 cells of about $300 \mu \mathrm{m}$ in diameter were generated and treated with $0.1 \%$ DMSO or CNX-2006 at the NCI-H1975 GI ${ }_{50}$. Measurement and analysis were performed as previously described [55].

\section{Generation of CNX-2006-resistant cells}

NCI-H1975 were cultured with increasing concentrations of CNX-2006 in step-wise fashion until cells emerged that were growing in the presence of 1 $\mu \mathrm{M}$ CNX-2006. Cells were initially treated with a drug concentration at which $30 \%$ of the cells were growth inhibited or killed $\left(\mathrm{GI}_{30}\right)$ and when cells resumed normal growth patterns, the drug concentration was increased.

\section{RNA-sequencing}

Quantification and quality assessment for RNA extracted from NCI-H1975 and H1975CR cells were performed with a Bioanalyzer (Agilent, Santa Clara, CA). Sequencing libraries were constructed with a TruSeq 
mRNA Library Preparation Kit using poly-A-enriched RNA (Illumina, San Diego, CA). Captured libraries were sequenced on an Illumina HiSeq2000 platform with a single-end 50-base protocol. Sequences were aligned to the human genome (Hg19) with TopHat2 [56]. HTSeq was used to assess the number of uniquely assigned reads for each gene; expression values were then normalized to $10^{7}$ total reads and $\log _{2}$ transformed (results are provided as Supplementary Dataset 1). TopHat2 [http://tophat.cbcb. umd.edu/index.shtml] and Cufflinks [http://cufflinks. cbcb.umd.edu/] were used to compare the two-condition transcriptomes $[56,57]$. The results were visualized by CummeRbund [http://compbio.mit.edu/cummeRbund/].

\section{Kinase inhibition profile \& peptide substrate array}

Kinase inhibition profile of CNX-2006 was performed by Reaction Biology Corporation (RBC, Malvern, PA). Differential kinase activity in NCI-H1975 and H1975CR cells was analyzed by a kinase peptide substrate array (PamChip $\AA$, PamGene International, 's-Hertogenbosch, The Netherlands) as previously described [55].

\section{Monitoring of NF-kB activation}

The Cignal NF-kB Pathway Reporter Assay Kit (GFP) (Qiagen, Hilden, Germany) was used to assess NF$\mathrm{kB}$ activity in NCI-H1975 and H1975CR according to manufacturer's specifications. A mixture of a constitutively expressing GFP construct was used as positive control to assess transfection efficiency. A negative control, in which GFP expression was controlled by a basal promoter, was used to identify pathway-specific effects and determine background reporter activity. Expression of the GFP reporter was monitored via FACS at $488 \mathrm{~nm}$ for excitation and 530/30 $\mathrm{nm}$ for emission.

\section{ELISA assay}

Phosphorylation and expression levels of intracellular proteins were determined by ELISA assays according to manufacturers' protocols. The following kits were used: PathScan ${ }^{\circledR}$ Phospho-IKK $\beta$ (Ser177/181) Sandwich ELISA Kit \#7080 (Cell Signaling Technology, Danvers, MA); Human Phospho-ATM (S1981) DuoSet IC (R\&D Systems, Minneapolis, MN); phospho$\mathrm{I} \kappa \mathrm{B} \alpha *[\mathrm{pS} 32] \# \mathrm{KHO} 0221$ and total $\mathrm{I} \kappa \mathrm{B} \alpha$ \#KHO0221 (Invitrogen).

\section{Statistical analysis}

All experiments were performed in triplicate and repeated at least twice. Data are expressed as mean values \pm SEM and analyzed using the two-tailed Student's t-test or ANOVA followed by the Bonferroni's multiple comparison test by using Prism (GraphPad Software). RNA-seq data were analyzed by beta-binomial model as previously reported [23].

\section{ACKNOWLEDGMENTS}

We thank Dr. T.V. Pham, Dr. D. Chiasserini, Dr. R.J. Honeywell, Dr. D. Sie, A. van der Velde, and Dr. P.G. Petronini for assistance in processing the transcriptome data and constructive discussions; Dr. M. Baevsky, Dr. A.Dubrovskiy, Dr. Z. Zhendong, Dr. Z. Wang, Dr. D. Van Kalken and Dr. M. Labenski for drug design and data collection.

\section{DISCLOSURES}

A patent relating to EGFR-T790M mutation testing was licensed on behalf of WP and others by Memorial Sloan-Kettering Cancer Center to MolecularMD. Authors affiliated with Celgene Avilomics Research, Bedford, MA 01730 received financial and stock option incentives from a publically traded company (Celgene). The source of funding did not have any influence on the design and the analysis of the results.

\section{GRANT SUPPORT}

This work was supported by Italian Foundation for Cancer Research (FIRC - Fellowship to EG), FP7REGPOT-2012-CT2012-31637-IMBRAIN (Fellowship to LGL), Nederlandse Organisatie voor Wetenschappelijk Onderzoek - Netherlands Organization for Scientific Research (NWO), Veni grant, project number 91611046, and AIRC Marie-Curie/Start-Up grant (to EG). Some of this work was supported in part by grants from the $\mathrm{V}$ Foundation (to WP) and the NCI (R01-CA121210, P01CA129243, and U54-CA143798 to WP). WP received additional support from Vanderbilt's Specialized Program of Research Excellence in Lung Cancer grant (CA90949) and the VICC Cancer Center Support Grant (P30CA68485).

\section{CONFLICTS OF INTEREST STATEMENT}

No potential conflicts of interest were disclosed.

\section{REFERENCES}

1. Lynch T.J., Bell D.W., Sordella R., Gurubhagavatula S., 
Okimoto R.A., Brannigan B.W., Harris P.L., Haserlat S.M., Supko J.G., Haluska F.G., Louis D.N., Christiani D.C., Settleman J., Haber D.A. Activating mutations in the epidermal growth factor receptor underlying responsiveness of non-small-cell lung cancer to gefitinib. N Engl J Med. 2004;350:2129-39.

2. Gazdar A.F., Minna J.D. Inhibition of EGFR signaling: all mutations are not created equal. PLoS Med. 2005;2:e377.

3. Sutto L., Gervasio F.L. Effects of oncogenic mutations on the conformational free-energy landscape of EGFR kinase. Proc Natl Acad Sci U S A. 2013;110:10616-21.

4. Kobayashi S., Boggon T.J., Dayaram T., Janne P.A., Kocher O., Meyerson M., Johnson B.E., Eck M.J., Tenen D.G., Halmos B. EGFR mutation and resistance of non-small-cell lung cancer to gefitinib. N Engl J Med. 2005;352:786-92.

5. Pao W., Miller V.A., Politi K.A., Riely G.J., Somwar R., Zakowski M.F., Kris M.G., Varmus H. Acquired resistance of lung adenocarcinomas to gefitinib or erlotinib is associated with a second mutation in the EGFR kinase domain. PLoS Med. 2005;2:e73.

6. Sun J.M., Ahn M.J., Choi Y.L., Ahn J.S., Park K. Clinical implications of T790M mutation in patients with acquired resistance to EGFR tyrosine kinase inhibitors. Lung Cancer. 2013;82:294-8.

7. Yun C.H., Mengwasser K.E., Toms A.V., Woo M.S., Greulich H., Wong K.K., Meyerson M., Eck M.J. The T790M mutation in EGFR kinase causes drug resistance by increasing the affinity for ATP. Proc Natl Acad Sci U S A. 2008;105:2070-5.

8. Galvani E., Alfieri R., Giovannetti E., Cavazzoni A., La Monica S., Galetti M., Fumarola C., Bonelli M., Mor M., Tiseo M., Peters G.J., Petronini P.G., Ardizzoni A. Epidermal growth factor receptor tyrosine kinase inhibitors: current status and future perspectives in the development of novel irreversible inhibitors for the treatment of mutant non-small cell lung cancer. Curr Pharm Des. 2013;19:81832.

9. Ercan D., Zejnullahu K., Yonesaka K., Xiao Y., Capelletti M., Rogers A., Lifshits E., Brown A., Lee C., Christensen J.G., Kwiatkowski D.J., Engelman J.A., Jänne P.A. Amplification of EGFR T790M causes resistance to an irreversible EGFR inhibitor. Oncogene. 2010;29:2346-56.

10. Kim Y., Ko J., Cui Z., Abolhoda A., Ahn J.S., Ou S.H., Ahn M.J., Park K. The EGFR T790M mutation in acquired resistance to an irreversible second-generation EGFR inhibitor. Mol Cancer Ther. 2012;11:784-91.

11. Sequist L.V., Besse B., Lynch T.J., Miller V.A., Wong K.K., Gitlitz B., Eaton K., Zacharchuk C., Freyman A., Powell C., Ananthakrishnan R., Quinn S., Soria J.C. Neratinib, an irreversible pan-ErbB receptor tyrosine kinase inhibitor: results of a phase II trial in patients with advanced non-small-cell lung cancer. J Clin Oncol. 2010;28:3076-83.

12. Walter A.O., Tjin Tham S.R., Haringsma H.J., Ohashi K., Sun J., Lee K., Dubrovskiy A., Labenski M., Zhu Z., Wang
Z., Sheets M., St Martin T., Karp R., et al. Discovery of a mutant-selective covalent inhibitor of EGFR that overcomes T790M-mediated resistance in NSCLC. Cancer Discov. 2013;3:1404-15.

13. Cross D.A., Ashton S.E., Ghiorghiu S., Eberlein C., Nebhan C.A., Spitzler P.J., Orme J.P., Finlay M.R., Ward R.A., Mellor M.J., Hughes G., Rahi A., Jacobs V.N., et al. AZD9291, an irreversible EGFR TKI, overcomes T790Mmediated resistance to EGFR inhibitors in lung cancer. Cancer Discov. 2014;4:1046-61.

14. Ma H., Deacon S., Horiuchi K. The challenge of selecting protein kinase assays for lead discovery optimization. Expert Opin Drug Discov. 2008;3:607-621.

15. Engelman J.A., Zejnullahu K., Mitsudomi T., Song Y., Hyland C., Park J.O., Lindeman N., Gale C.M., Zhao X., Christensen J., Kosaka T., Holmes A.J., Rogers A.M., et al. MET amplification leads to gefitinib resistance in lung cancer by activating ERBB3 signaling. Science. 2007;316:1039-43.

16. Su H., Seimbille Y., Ferl G.Z., Bodenstein C., Fueger B., Kim K.J., Hsu Y.T., Dubinett S.M., Phelps M.E., Czernin J., Weber W.A. Evaluation of [(18)F]gefitinib as a molecular imaging probe for the assessment of the epidermal growth factor receptor status in malignant tumors Eur. J. Nucl. Med. Mol. Imaging. 2008;35:1089- 1099.

17. Li X., Kamenecka T.M., Cameron M.D. Bioactivation of the epidermal growth factor receptor inhibitor gefitinib: implications for pulmonary and hepatic toxicities. Chem Res Toxicol. 2009;22:1736-1742.

18. Galetti M., Alfieri R.R., Cavazzoni A., La Monica S., Bonelli M., Fumarola C., Mozzoni P., De Palma G., Andreoli R., Mutti A., Mor M., Tiseo M., Ardizzoni A., Petronini P.G. Functional characterization of gefitinib uptake in non-small cell lung cancer cell lines. Biochem Pharmacol. 2010;80:179-187.

19. Da Silva C.G., Honeywell R.J., Dekker H., Peters G.J. Physicochemical properties of novel protein kinase inhibitors in relation to their substrate specificity for drug transporters. Expert Opin Drug Metab Toxicol. 2015;29:115.

20. Kang J.U., Koo S.H., Kwon K.C., Park J.W., Jung S.S. Gain of the EGFR gene located on $7 \mathrm{p} 12$ is a frequent and early event in squamous cell carcinoma of the lung. Cancer Genet Cytogenet. 2008;184:31-7.

21. Hayashi M., Kawauchi S., Ueda K., Kaneda Y., Oga A., Furuya T., Hamano K., Sasaki K. Genomic alterations detected by comparative genomic hybridization in primary lung adenocarcinomas with special reference to the relationship with DNA ploidy. Oncol Rep. 2005;14:142935.

22. Young R.P., Whittington C.F., Hopkins R.J., Hay B.A., Epton M.J., Black P.N., Gamble G.D. Chromosome 4q31 locus in COPD is also associated with lung cancer. Eur Respir J. 2010;36:1375-82. 
23. Pham T.V., Piersma S.R., Warmoes M., Jimenez C.R. On the beta-binomial model for analysis of spectral count data in label-free tandem mass spectrometry-based proteomics. Bioinformatics. 2010;26:363-9.

24. Heideman D.A., Lurkin I., Doeleman M., Smit E.F., Verheul H.M., Meijer G.A., Snijders P.J., Thunnissen E., Zwarthoff E.C. KRAS and BRAF mutation analysis in routine molecular diagnostics: comparison of three testing methods on formalin-fixed, paraffin-embedded tumorderived DNA. J Mol Diagn. 2012;14:247-55.

25. Cortot A.B., Repellin C.E., Shimamura T., Capelletti M., Zejnullahu K., Ercan D., Christensen J.G., Wong K.K., Gray N.S., Jänne P.A. Resistance to irreversible EGF receptor tyrosine kinase inhibitors through a multistep mechanism involving the IGF1R pathway. Cancer Res. 2013;73:834-43.

26. Ercan D., Xu C., Yanagita M., Monast C.S., Pratilas C.A., Montero J., Butaney M., Shimamura T., Sholl L., Ivanova E.V., Tadi M., Rogers A., Repellin C., et al. Reactivation of ERK signaling causes resistance to EGFR kinase inhibitors. Cancer Discov. 2012;2:934-47.

27. Sequist L.V., Waltman B.A., Dias-Santagata D., Digumarthy S., Turke A.B., Fidias P., Bergethon K., Shaw A.T., Gettinger S., Cosper A.K., Akhavanfard S., Heist R.S., Temel J., et al. Genotypic and histological evolution of lung cancers acquiring resistance to EGFR inhibitors. Sci Transl Med. 2011;3:75ra26.

28. Zhang Z., Lee J.C., Lin L., Olivas V., Au V., LaFramboise T., Abdel-Rahman M., Wang X., Levine A.D., Rho J.K., Choi Y.J., Choi C.M., Kim S.W., et al. Activation of the AXL kinase causes resistance to EGFR-targeted therapy in lung cancer. Nat Genet. 2012;44:852-60.

29. Byers L.A., Diao L., Wang J., Saintigny P., Girard L., Peyton M., Shen L., Fan Y., Giri U., Tumula P.K., Nilsson M.B., Gudikote J., Tran H., et al. An epithelialmesenchymal transition gene signature predicts resistance to EGFR and PI3K inhibitors and identifies Axl as a therapeutic target for overcoming EGFR inhibitor resistance. Clin Cancer Res. 2013;19:279-90.

30. Bivona T.G., Hieronymus H., Parker J., Chang K., Taron M., Rosell R., Moonsamy P., Dahlman K., Miller V.A., Costa C., Hannon G., Sawyers C.L. FAS and NF-kappaB signalling modulate dependence of lung cancers on mutant EGFR. Nature. 2011;471:523-6.

31. Hayden M.S., Ghosh S. Shared principles in NF-kappaB signaling. Cell. 2008 Feb 8;132:344-62.

32. Mukherjee B., Tomimatsu N., Amancherla K., Camacho C.V., Pichamoorthy N., Burma S. The dual PI3K/mTOR inhibitor NVP-BEZ235 is a potent inhibitor of ATM- and DNA-PKCs-mediated DNA damage responses. Neoplasia. 2012;14:34-43.

33. Janssens S., Tschopp J. Signals from within: the DNAdamage-induced NF-[kappa]B response. Cell Death Differ. 2006;13:773-84.
34. Lee H.J., Schaefer G., Heffron T.P., Shao L., Ye X., Sideris S., Malek S., Chan E., Merchant M., La H., Ubhayakar S., Yauch R.L., Pirazzoli V., et al. Noncovalent wildtype-sparing inhibitors of EGFR T790M. Cancer Discov. 2013;3:168-81.

35. Zhou W., Ercan D., Chen L., Yun C.H., Li D., Capelletti M., Cortot A.B., Chirieac L., Iacob R.E., Padera R., Engen J.R., Wong K.K., Eck M.J., et al. Novel mutant-selective EGFR kinase inhibitors against EGFR T790M. Nature. 2009;462:1070-4.

36. Camus P., Kudoh S., Ebina M. Interstitial lung disease associated with drug therapy. Br J Cancer. 2004;91 Suppl 2:S18-S23.

37. Herbst R.S., LoRusso P.M., Purdom M., Ward D. Dermatologic side effects associated with gefitinib therapy: clinical experience and management. Clin Lung Cancer. 2003;4:366-9.

38. Shien K., Toyooka S., Yamamoto H., Soh J., Jida M., Thu K.L., Hashida S., Maki Y., Ichihara E., Asano H., Tsukuda K., Takigawa N., Kiura K., et al. Acquired Resistance to EGFR Inhibitors Is Associated with a Manifestation of Stem Cell-like Properties in Cancer Cells. Cancer Res. 2013;73:3051-61.

39. Ogino A., Kitao H., Hirano S., Uchida A., Ishiai M., Kozuki T., Takigawa N., Takata M., Kiura K., Tanimoto M. Emergence of epidermal growth factor receptor T790M mutation during chronic exposure to gefitinib in a non small cell lung cancer cell line. Cancer Res. 2007;67:7807-14.

40. Ercan D., Xie T., Capelletti M., Gray N.S., Janne P.A. Novel EGFR mutations that cause drug resistance to irreversible pyrimidine but not quinazoline based EGFR inhibitors. Cancer Res. 2012;72:4832. AM2012-4832.

41. Chen X., Wang Y., Xia H., Wang Q., Jiang X., Lin Z., Ma Y., Yang Y., Hu M. Loss of E-cadherin promotes the growth, invasion and drug resistance of colorectal cancer cells and is associated with liver metastasis. Mol Biol Rep. 2012;39:6707-14.

42. Yoo S.B., Kim Y.J., Kim H., Jin Y., Sun P.L., Jheon S., Lee J.S., Chung J.H. Alteration of the E-cadherin/beta-Catenin Complex Predicts Poor Response to Epidermal Growth Factor Receptor-Tyrosine Kinase Inhibitor (EGFR-TKI) Treatment. Ann Surg Oncol. 2013;20 Suppl 3:S545-52.

43. Fonseca F.L., Azzalis L.A., Feder D., Nogoceke E., Junqueira V.B., Valenti V.E., de Abreu L.C. Adhesion molecules affected by treatment of lung cancer cells with epidermal growth factor. Lung. 2011;189:383-9.

44. La Monica S., Caffarra C., Saccani F., Galvani E., Galetti M., Fumarola C., Bonelli M., Cavazzoni A., Cretella D., Sirangelo R., Gatti R., Tiseo M., Ardizzoni A., et al. Gefitinib inhibits invasive phenotype and epithelialmesenchymal transition in drug-resistant NSCLC cells with MET amplification. PLoS One. 2013;8:e78656.

45. Stathopoulos G.T., Sherrill T.P., Cheng D.S., Scoggins R.M., Han W., Polosukhin V.V., Connelly L., Yull F.E., 
Fingleton B., Blackwell T.S. Epithelial NF-kappaB activation promotes urethane-induced lung carcinogenesis. Proc Natl Acad Sci U S A. 2007;104:18514-9.

46. Meylan E., Dooley A.L., Feldser D.M., Shen L., Turk E., Ouyang C., Jacks T. Requirement for NF-kappaB signalling in a mouse model of lung adenocarcinoma. Nature. 2009;462:104-7.

47. Alberti C., Pinciroli P., Valeri B., Ferri R., Ditto A., Umezawa K., Sensi M., Canevari S., Tomassetti A. Liganddependent EGFR activation induces the co-expression of IL-6 and PAI-1 via the NFkB pathway in advanced-stage epithelial ovarian cancer. Oncogene. 2012;31:4139-49.

48. De S., Dermawan J.K., Stark G.R. EGF receptor uses SOS1 to drive constitutive activation of $\mathrm{NF} \kappa \mathrm{B}$ in cancer cells. Proc Natl Acad Sci U S A. 2014;111:11721-6.

49. Lu T., Sathe S.S., Swiatkowski S.M., Hampole C.V., Stark G.R. Secretion of cytokines and growth factors as a general cause of constitutive NFkappaB activation in cancer. Oncogene. 2004;23:2138-45.

50. Sun S.C. Non-canonical NF-кB signaling pathway. Cell Res. 2011;21:71-85.

51. Tang X., Liu D., Shishodia S., Ozburn N., Behrens C., Lee J.J., Hong W.K., Aggarwal B.B., Wistuba I.I. Nuclear factor-kappaB (NF-kappaB) is frequently expressed in lung cancer and preneoplastic lesions. Cancer. 2006;107:263746.

52. Escobar M., Velez M., Belalcazar A., Santos E.S., Raez L.E. The role of proteasome inhibition in nonsmall cell lung cancer. J Biomed Biotechnol. 2011;2011:806506.

53. Ohashi K., Sequist L.V., Arcila M.E., Moran T., Chmielecki J., Lin Y.L., Pan Y., Wang L., de Stanchina E., Shien K., Aoe K., Toyooka S., Kiura K., et al. Lung cancers with acquired resistance to EGFR inhibitors occasionally harbor BRAF gene mutations but lack mutations in KRAS, NRAS, or MEK1. Proc Natl Acad Sci U S A. 2012;109:E2127-33.

54. Pao W., Miller V., Zakowski M., Doherty J., Politi K., Sarkaria I., Singh B., Heelan R., Rusch V., Fulton L., Mardis E., Kupfer D., Wilson R., et al. EGF receptor gene mutations are common in lung cancers from "never smokers" and are associated with sensitivity of tumors to gefitinib and erlotinib. Proc Natl Acad Sci U S A. 2004;101:13306-11.

55. Galvani E., Giovannetti E., Saccani F., Cavazzoni A., Leon L.G., Dekker H., Alfieri R.R., Carmi C., Mor M., Ardizzoni A., Petronini P.G., Peters G.J. Molecular mechanisms underlying the antitumor activity of 3-aminopropanamide irreversible inhibitors of the epidermal growth factor receptor in non-small cell lung cancer. Neoplasia. 2013;15:61-72.

56. Kim D., Pertea G., Trapnell C., Pimentel H., Kelley R., Salzberg S.L. TopHat2: accurate alignment of transcriptomes in the presence of insertions, deletions and gene fusions. Genome Biol. 2013;14:R36.

57. Trapnell C., Roberts A., Goff L., Pertea G., Kim D., Kelley
D.R., Pimentel H., Salzberg S.L., Rinn J.L., Pachter L. Differential gene and transcript expression analysis of RNA-seq experiments with TopHat and Cufflinks. Nat Protoc. 2012;7:562-78. 